\title{
Article \\ Effects of Trace Oxygen Content on Microstructure and Performances of Au-20Sn/Cu Solder Joints
}

\author{
Yang $\mathrm{Li}^{1, *}$, Di Wu ${ }^{1}$, Yabin Zhang ${ }^{1}$, Liujue Wang ${ }^{2}$ and Songbai Xue ${ }^{2}$ \\ 1 Nanjing Electronic Devices Institute, Nanjing 210016, China; 18256001401@sina.cn (D.W.); \\ xsh202009@sina.com (Y.Z.) \\ 2 College of Materials Science and Technology, Nanjing University of Aeronautics and Astronautics, \\ Nanjing 210016, China; wanglj@nuaa.edu.cn (L.W.); xuesb@nuaa.edu.cn (S.X.) \\ * Correspondence: renee881028@sina.com; Tel.: +86-025-6800-5412
}

Citation: Li, Y.; Wu, D.; Zhang, Y.; Wang, L.; Xue, S. Effects of Trace Oxygen Content on Microstructure and Performances of Au-20Sn/Cu Solder Joints. Crystals 2021, 11, 601. https://doi.org/10.3390/ cryst11060601

Academic Editors: Shanping Lu and Cyril Cayron

Received: 30 April 2021

Accepted: 24 May 2021

Published: 26 May 2021

Publisher's Note: MDPI stays neutral with regard to jurisdictional claims in published maps and institutional affiliations.

Copyright: (c) 2021 by the authors. Licensee MDPI, Basel, Switzerland. This article is an open access article distributed under the terms and conditions of the Creative Commons Attribution (CC BY) license (https:// creativecommons.org/licenses/by/ $4.0 /)$.
Abstract: The Au-20Sn solder is widely used in the packaging of high-end electronic products, and the requirement on the reliability of the solder joints is more and more strict with a continuous increase in the performance of the package products. As the oxygen content in the Au-Sn solder is a key factor dominating the quality of fluxless packaging, in this study, the wettability and spreading performance of the Au-20Sn solder with different oxygen contents and the interfacial microstructure, mechanical properties, gas tightness and ratio of soldering area of the Au-Sn/Cu solder joints prepared using these solders were comprehensively investigated to clarify the effects of trace oxygen content. The results reveal that the wetting and spreading performances of the solder decrease sharply with increasing oxygen conte[nt. When the oxygen content increased from 18 to $77 \mathrm{ppm}$, the spreading area of the solder on the $\mathrm{Cu}$ substrate decreased from 92.8 to $49.2 \mathrm{~mm}^{2}$, reducing by $47 \%$. Meanwhile, pores and microcracks appear in the solder joint with relatively high oxygen content, making the shear strength decrease from 56.6 to $31.7 \mathrm{MPa}$. The oxygen also greatly affects the gas tightness and ratio of soldering area. For the optical window packaged using Au-Sn solder containing $40 \mathrm{ppm}$ of oxygen, the leakage rate was higher than $5 \times 10^{-11} \mathrm{mbar} \cdot \mathrm{m}^{-3} \cdot \mathrm{s}^{-1}$ and cannot fulfill the requirements. With increasing oxygen content in the Au-Sn solder, the cleanliness of the chip packaged with these solders deteriorated, and the solder surface was obviously oxidized. When the oxygen content was $18 \mathrm{ppm}$, the ratio of soldering area was $92 \%$, but decreased sharply to $53 \%$ when the oxygen content increased to $77 \mathrm{ppm}$. It is demonstrated that an oxygen content lower than $27 \mathrm{ppm}$ is required for the $\mathrm{Au}-20 \mathrm{Sn}$ solder used in fluxless packaging.

Keywords: Au-20Sn solder; fluxless packaging; trace oxygen content; ratio of soldering area; gas tightness; shear strength

\section{Introduction}

Due to its superior thermal conductivity and electrical conductivity, excellent corrosion resistance and high fatigue resistance, the Au-20Sn solder has been widely used in the packaging of the military electronic products and some other high-end electronic products [1-4]. With the continuous increase in power and package density of the electronic products, the requirement on the reliability of the $\mathrm{Au}-\mathrm{Sn} / \mathrm{Cu}$ solder joints in these electronic products is more and more strict. A series of investigations on the manufacturing processes of the Au-20Sn solder and its key properties such as wettability and solderability have been conducted [5-7]; especially, the reliability of the Au-Sn/Cu solder joints has become a hotspot of the electronic packaging field.

The Au-Sn solder has good oxidation resistance and theoretically can meet the requirement of fluxless packaging, if the oxygen content in the solder is low enough. However, during the manufacture, transportation, storage, application and other processes, inevitably a trace oxygen will enter the solder. In this regard, a lot of research focuses on the effects of oxygen on solderability and reliability of the Au-Sn solder have been conducted. With 
the increased content of oxygen, surface tension of the liquid solder increases and the wettability decreases obviously [8,9]. Besides, the oxygen entrained into the solder also results in a large number of defects in the solder joint, which decreases the reliability of the package products $[10,11]$. Kuhmann et al. revealed the oxidation and reduction kinetics of the Au-20Sn solder and found that the Au-20Sn solder shows good wettability when it is used in fluxless soldering in $\mathrm{H}_{2}$ atmosphere [12]. Although some measures such as using flux can reduce the oxygen content in the soldering system, fluxless packaging will be inevitable for some key electronic components, such as flip chip, power-integrated circuit module and MEMS devices $[5,13,14]$. Since the oxygen content in the Au-Sn solder is a key factor that dominates the quality of fluxless soldering, it is essential to clarify the effects of oxygen content on reliability of the fluxless packaged Au-20Sn solder joints. As a basic basis to evaluate the packaging quality, it is of great academic and practical importance to investigate the effects of oxygen content in the Au-Sn solder on the ratio of the soldering area, mechanical properties and gas tightness of the solder joints.

In this study, the oxygen contents of the Au-20Sn solders from different manufacturers were measured firstly, then these Au-Sn solders were chosen for soldering, and the influences of oxygen content on wettability and spreading performance of the solder, the interfacial microstructure, joint strength, gas tightness and ratio of soldering area of the $\mathrm{Au}-\mathrm{Sn} / \mathrm{Cu}$ solder joints were studied. Based on that, the relationship between oxygen content and reliability of the Au-Sn/Cu solder joint was evaluated.

\section{Experimental Procedure}

The Au-20Sn solders used in this study were purchased from different manufacturers. Before the experiments, the oxygen contents in these solders were detected firstly by a LECO-ONH836 NHO analyzer, and the result is shown in Table 1. Then, the Au-20Sn solders with different oxygen contents were selected for further experiments.

Table 1. Oxygen contents of Au-20Sn solders from different manufacturers.

\begin{tabular}{cccccc}
\hline Serial Number of Manufacturers & $\mathbf{1}$ & $\mathbf{2}$ & $\mathbf{3}$ & $\mathbf{4}$ & $\mathbf{5}$ \\
\hline Oxygen Content/ppm & 18 & 27 & 40 & 53 & 77 \\
\hline
\end{tabular}

The wetting and spreading tests of the Au-20Sn solder were operated according to China's national standard GB/T11364-2008. The substrate is Cu plates with a size of $40 \times 40 \times 1 \mathrm{~mm}^{3}$. Before the wetting test, the $\mathrm{Cu}$ plates were cleaned in ethanol for $5 \mathrm{~min}$ by an ultrasonic cleaning machine (ST13, GT Sonic Co., Ltd, Shenzhen, China). The Au-20Sn solder blocks each weight $0.2 \mathrm{~g}$ were placed at the center of the Cu plates, and then, the $\mathrm{Cu}$ plates were put into a vacuum furnace(CUT180, Acxvac Co., Ltd, Kunshan, China) and held at $310{ }^{\circ} \mathrm{C}$ for $1 \mathrm{~min}$. After cooling, the samples were photographed and the spreading areas were measured using an Image Pro Plus software (Media Cybernetics Co., Ltd, Rockville, MD, USA). Three specimens were tested for each kind of solder to get an average value.

The size of the $\mathrm{Cu}$ strips for preparation of the lap solder joints used as shear specimens is $30 \times 5 \times 1 \mathrm{~mm}^{3}$. Before soldering, the $\mathrm{Cu}$ substrate was ground by $\mathrm{SiC}$ abrasive paper and cleaned in an acetone solution.

All the soldering processes were conducted by a vacuum furnace at a vacuum degree of $1 \times 10^{-4}$ mbar and a soldering temperature of $310^{\circ} \mathrm{C}$, and the heating rate is $10^{\circ} \mathrm{C} / \mathrm{min}$. Cross sections of some solder joints were carefully ground and polished, then the microstructures of the joint interfaces were observed by a field emission scanning electron microscope (FE-SEM, ZEISS $\Sigma$ IGMA 500, Jena, Germany), and the composition at different areas of the solder joints were analyzed by an X-ray energy dispersive spectrometer (EDS, INCA X-Act, Bradford, British) equipment on the SEM. Shear tests of the solder joints were carried out according to the China's National Standard GB/T11363-2008 using a SANS-CMT5105 microcomputer (Shenzhen SANS Testing Machine Co., Ltd, Shenzhen, 
China) controlled electronic universal tensile testing machine, and the beam movement rate was $2 \mathrm{~mm} / \mathrm{min}$. Five parallel shear samples were tested for each group.

The chips and flat sapphire optical windows were packaged under the same conditions of the solder joints. The gas tightness of the packaged optical windows was detected by a ZQJ-542 helium mass spectrometer leak detector (Guangzhou Minder-Highetech Co., Ltd, Guangzhou, China) and the leakage rate was recorded and compared with the reference values specified in the China's National Military Standard GJB548B-2005. X-ray fluoroscopy was used to get the perspective images of solder layers in the chips, and the ratio of soldering area was calculated by dividing the actual soldering area on the X-ray projection images to the theoretical soldering area.

\section{Results and Discussion}

\subsection{Effect of Oxygen Content on Wettability of the Solder}

Generally, when a liquid solder can react with the substrate to form solid solution or intermetallic compounds (IMC), the solder can wet and spread on the substrate smoothly, because the formation of the new phases will decrease the system Gibbs free energy. Whereas, the oxides on the surface of the solder will show a very negative effect during the wetting and spreading processes of the solder on the substrate.

Figure 1 shows the spreading morphologies of the Au-20Sn solders with different oxygen contents. Obviously, with the increase in oxygen content, the spreading area decreased significantly and the edge of the solder became less smooth. The measured spreading areas of the Au-20Sn solders on the Cu plate are shown in Figure 2, in which it can be found that the spreading area decreases continuously with increasing oxygen content. When the oxygen content was $18 \mathrm{ppm}$, the spreading area reached the highest value of $92.8 \mathrm{~mm}^{2}$ and decreased to $90.9 \mathrm{~mm}^{2}$ when the oxygen content increased to $27 \mathrm{ppm}$. For the solder with $40 \mathrm{ppm}$ of oxygen, the spreading area decreased to $78.4 \mathrm{~mm}^{2}$, $15.5 \%$ lower than that of the solder with $18 \mathrm{ppm}$ of oxygen. With a further increase in oxygen content, the spreading area decreased sharply. When the oxygen content increased to $77 \mathrm{ppm}$, the spreading area was $47 \%$ lower than that of the solder with $18 \mathrm{ppm}$ of oxygen, only $49.2 \mathrm{~mm}^{2}$.
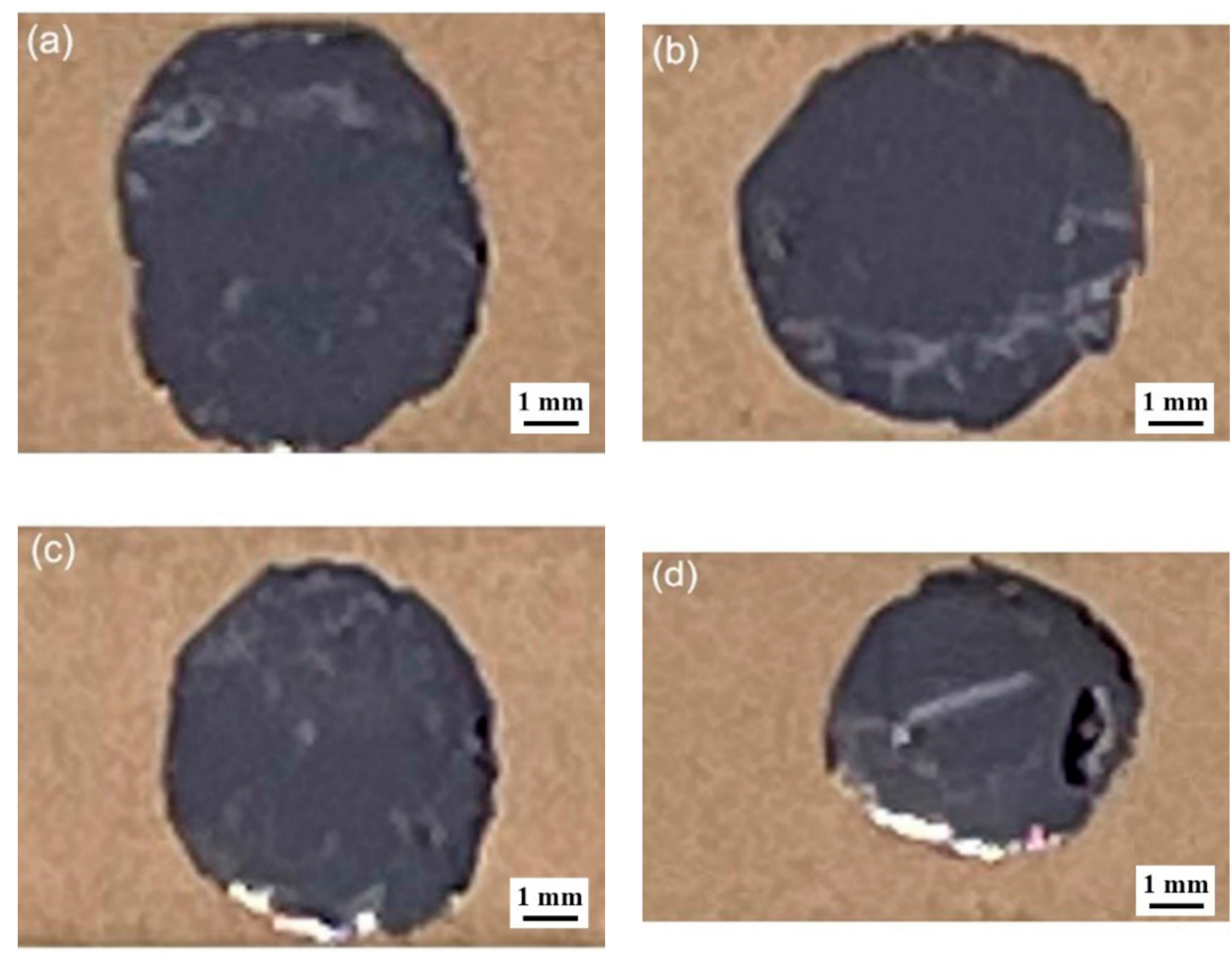

Figure 1. Cont. 


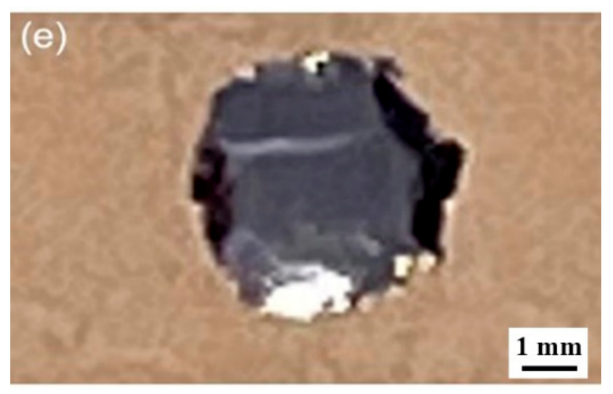

Figure 1. Spreading morphologies of Au-20Sn solders with different oxygen contents on the $\mathrm{Cu}$ plate: (a) 18 ppm, (b) 27 ppm, (c) 40 ppm, (d) 53 ppm, (e) 77 ppm.

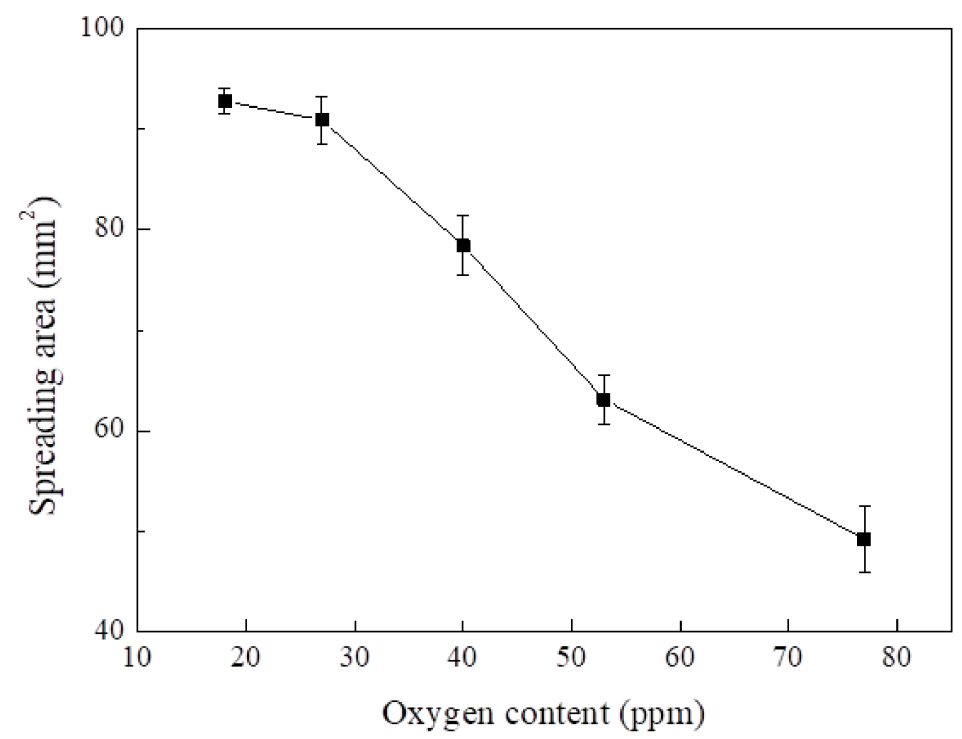

Figure 2. Evolution in spreading area of the Au-20Sn solder on $\mathrm{Cu}$ plate with increasing oxygen content in the solder.

Previous investigations have demonstrated that the oxygen at the surface of the Au-Sn solder exists mainly in the forms of $\mathrm{SnO}$ and $\mathrm{SnO}_{2}$ [15]. On one hand, the oxide film at the surface of the liquid Au-Sn solder increases the surface tension and decreases the wetting and spreading tendency. On the other hand, the oxides with high melting points increase the viscosity of the liquid solder and decrease the fluidity, which becomes a blocking force for spreading, making the flow of the liquid solder slow down or even stop [16]. Therefore, the wettability and spreading performance of the Au-20Sn solder decreases with the increase in oxygen content.

\subsection{Effects of Oxygen Content on Interfacial Microstructure and Strength of Solder Joints}

The cross-sectional images of the Au-Sn/Cu solder joints prepared using Au-20Sn solders with different oxygen contents are shown in Figure 3. It can be found that IMC layers are formed at all the $\mathrm{Au}-20 \mathrm{Sn} / \mathrm{Cu}$ interfaces, which were identified to be $\zeta-(\mathrm{Au}, \mathrm{Cu})_{5} \mathrm{Sn}$ by EDS and consistent with the previous reports [17]. For the interface soldered by the Au-Sn solder containing $18 \mathrm{ppm}$ of oxygen, no obvious pores or microcracks were observed, as in Figure $3 \mathrm{a}$, while a few micropores have appeared at the interface prepared by the solder with $27 \mathrm{ppm}$ of oxygen (see Figure $3 \mathrm{~b}$ ). When the oxygen content increased to $40 \mathrm{ppm}$, more pores appeared around the joint interface, as presented in Figure 3c. With further increase in oxygen content, the size of the pores increased gradually. Moreover, the adjacent pores propagate and connect with each other, forming cracks along the joint interface, as shown in Figure 3d,e. These findings suggest that a small change in oxygen content in the Au-20Sn solder will have a significant effect on microstructure of the fluxless packaged 
solder joint. As the oxygen in the solder exists mainly as oxides that covers the solder surface, if there is no flux, the oxides film will not be eliminated after melting of the solder and exist between the solder and the substrate, forming inclusions at the joint interface after solidification. Meanwhile, the gas elements dissolved into the solder cannot escape from the molten solder during the soldering process, resulting in the formation of the small pores. These defects can easily transform into microcracks under residual stress.
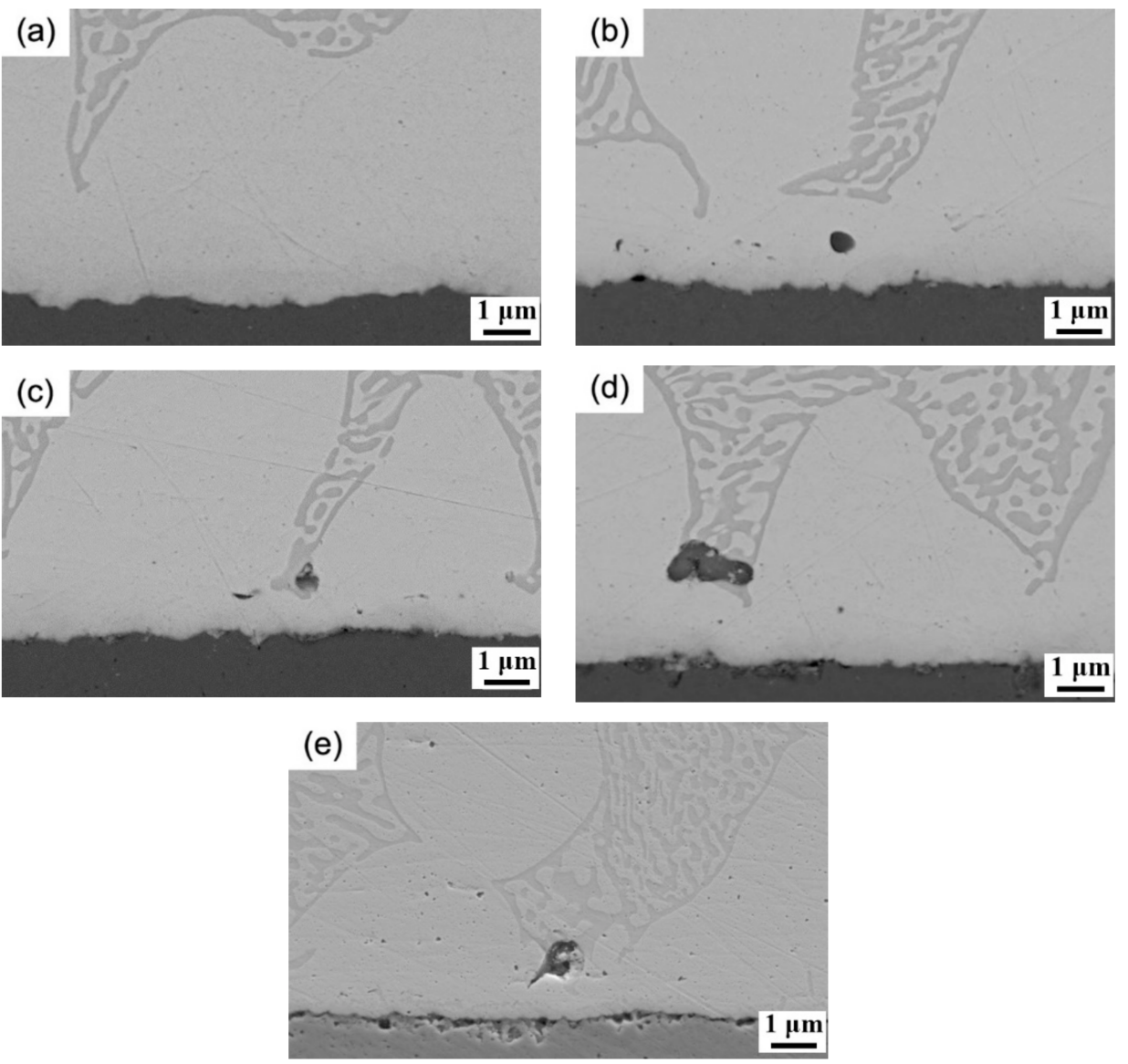

Figure 3. Morphologies of the Au-Sn/Cu joint interfaces soldered by Au-20Sn solders with the oxygen content of: (a) 18 ppm, (b) 27 ppm, (c) 40 ppm, (d) 53 ppm, (e) 77 ppm.

Shear strength of the Au-20Sn/Cu solder joints prepared with solders containing different amounts of oxygen is exhibited in Figure 4. With the oxygen content increased from 18 to $77 \mathrm{ppm}$, the shear strength decreased by $44 \%$, from the top value of 56.6 to 31.7 $\mathrm{MPa}$, which is consistent with the deterioration trend in the microstructure of the solder joints. Besides, the shear strength was close to the results reported by some early literatures, although the test conditions were not so identical $[18,19]$. The pores and microcracks greatly decrease the bonding strength between the solder, interfacial IMC and the substrate and further decrease the shear strength, which can also be proved by the fracture morphologies shown in Figure 5. As shown in Figure 5a, there were many small pores on the fracture surface when the oxygen content was only $18 \mathrm{ppm}$. With increasing oxygen content, the number and size of pores were gradually raised. When the oxygen content was above 40 ppm, not only pores but also micro-cracks formed, as shown in Figure $5 d$,e, which corresponds to the microstructure observation. 


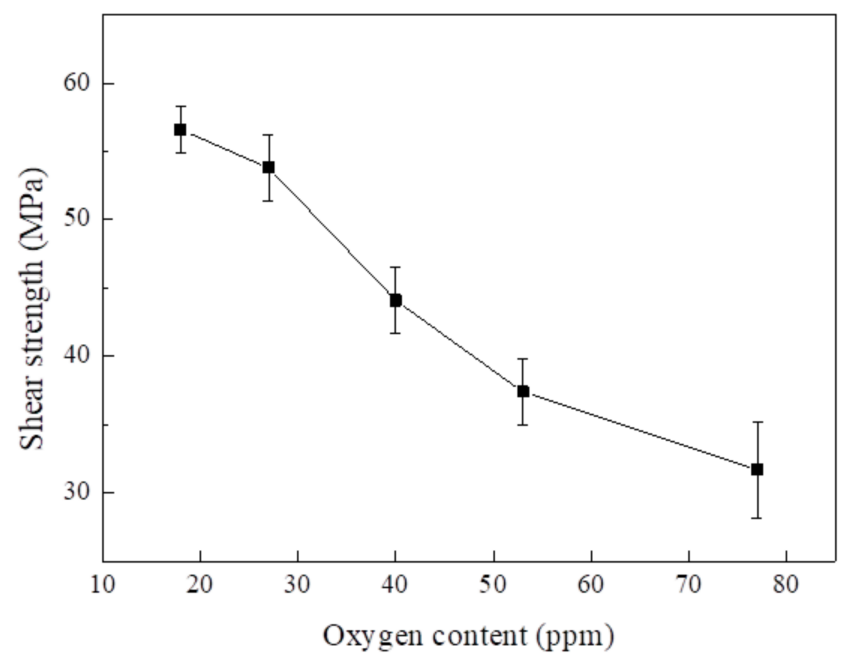

Figure 4. Evolution in shear strength of the $\mathrm{Au}-\mathrm{Sn} / \mathrm{Cu}$ joints with increasing oxygen content in the solder.
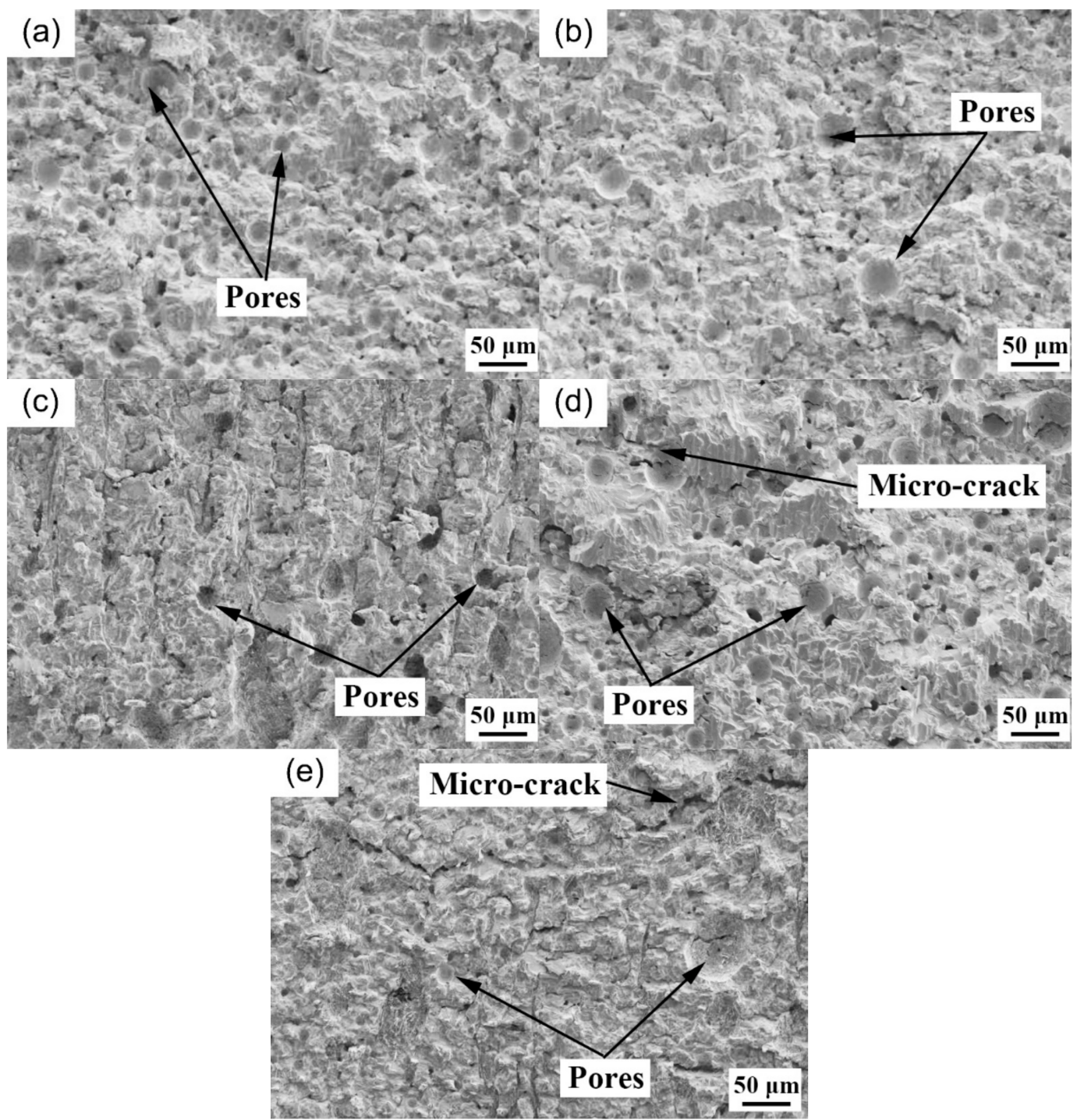

Figure 5. Fracture morphologies of $\mathrm{Au}-\mathrm{Sn} / \mathrm{Cu}$ solder joints with increasing oxygen content in the solder: (a) $18 \mathrm{ppm}$, (b) 27 ppm, (c) 40 ppm, (d) 53 ppm, (e) 77 ppm. 


\subsection{Effect of Oxygen Content on Air Tightness}

The power devices applied in space environment or military field usually need to service in harsh conditions such as high temperature, high humidity or acid-base conditions for a long time, and excellent radiation resistance and adverse environment resistance are required for the hybrid microelectronic modules. Therefore, hermetical packaging is necessary for these modules, in order to ensure the performance and reliability of the internal circuits and components in the service environment [20,21].

Table 2 lists the leakage rates of the devices packaged using Au-20Sn solders with different contents of oxygen. As in the table, the helium leakage rate increases with increasing oxygen content, i.e., the gas tightness of the package devices decreases gradually. When the oxygen content was lower than $27 \mathrm{ppm}$, the leakage rate was more than two orders of magnitude lower than the reference value, showing superior gas tightness. For the device packaged using the solder containing $40 \mathrm{ppm}$ of oxygen, the leakage rate was close to the reference value, but we cannot guarantee the qualified rate of the package devices in practical production. When the oxygen content was higher, the gas tightness decreased sharply and will not fulfill the requirement of China's National Military Standard GJB548B-2005 "Test methods and procedures for microelectronic devices" on package gas tightness.

Table 2. Leakage rates of package devices using Au-20Sn solders with different contents of oxygen.

\begin{tabular}{cccc}
\hline \multirow{2}{*}{ Oxygen Content/ppm } & \multicolumn{2}{c}{ Leakage Rate/Mbar. $\mathbf{m}^{-\mathbf{3}} \cdot \mathbf{s}^{-\mathbf{1}}$} & \multirow{2}{*}{ Qualified } \\
\cline { 2 - 3 } & Test Value & Reference Value & \\
\hline 18 & $6.4 \times 10^{-14}$ & & Yes \\
27 & $8.5 \times 10^{-13}$ & & Yes \\
40 & $5.2 \times 10^{-11}$ & $5 \times 10^{-11}$ & No \\
53 & $1.3 \times 10^{-10}$ & & No \\
77 & $7.7 \times 10^{-8}$ & & No \\
\hline
\end{tabular}

\subsection{Effect of Oxygen Content on Ratio of Soldering Area}

The reliability of solder joints is decisive for lifetime of the power devices. Although the Au-20Sn solder has good thermal conductivity and can act as a heat dissipation carrier when it is directly connected to the chip, it will be difficult for the solder to fully play its good heat dissipation property if the ratio of the soldering area is not ideal. The ratio of the soldering area of a solder joint is the ratio of the actual soldering area to the theoretical soldering area, which is an important index to judge the soldering quality and has an important influence on the physical and mechanical properties of the solder joints [22]. Therefore, the reliability of a solder joint is closely related to its ratio of soldering area. According to China's National Military Standard GJB548B-2005, when the ratio of void in a solder joint is higher than $50 \%$, or a single void crosses the whole length/width of a semiconductor chip exceeds $10 \%$ of the whole predetermined contact area, the soldering product will be considered to be unqualified.

To reveal the effect of oxygen content in the Au-20Sn solder on reliability of the solder joint, X-ray inspection of the solder joints was conducted to get their ratio of soldering area. Figure $6 a, c, e, g, i$ show the appearances of chips packaged with Au-Sn solders with different oxygen contents. When the oxygen contents were 18 and $27 \mathrm{ppm}$, the appearances of the chips were fine and clean, and the solder at the edge was smooth and continuous, with no obvious overflow or oxidation. With increasing oxygen content, the appearance of cleanliness on the chip gradually became worse, and the solder edge became uneven. In addition, surface oxidation of solder was more and more obvious, and the soldering quality worsened. The X-ray flaw detection images corresponding to the chip appearance are presented in Figure $6 \mathrm{~b}, \mathrm{~d}, \mathrm{f}, \mathrm{h}, \mathrm{j}$, in which the gray-white area indicates the void area in the solder layer. It is obvious that with increasing oxygen content, the void area and size of each void increase. The ratio of soldering area of the chips packaged using solders 
with different oxygen contents is shown in Figure 7 . When the oxygen contents were 18 and 27 ppm, the ratio of the soldering area was 92 and 88\%, respectively, indicating that the soldering quality is quite high. With a further increase in oxygen content, the ratio of soldering area decreased sharply. For the chip prepared using solder with $77 \mathrm{ppm}$ of oxygen, the ratio of the soldering area decreased to $53 \%$, and the structure continuity of the solder joints decreased greatly.
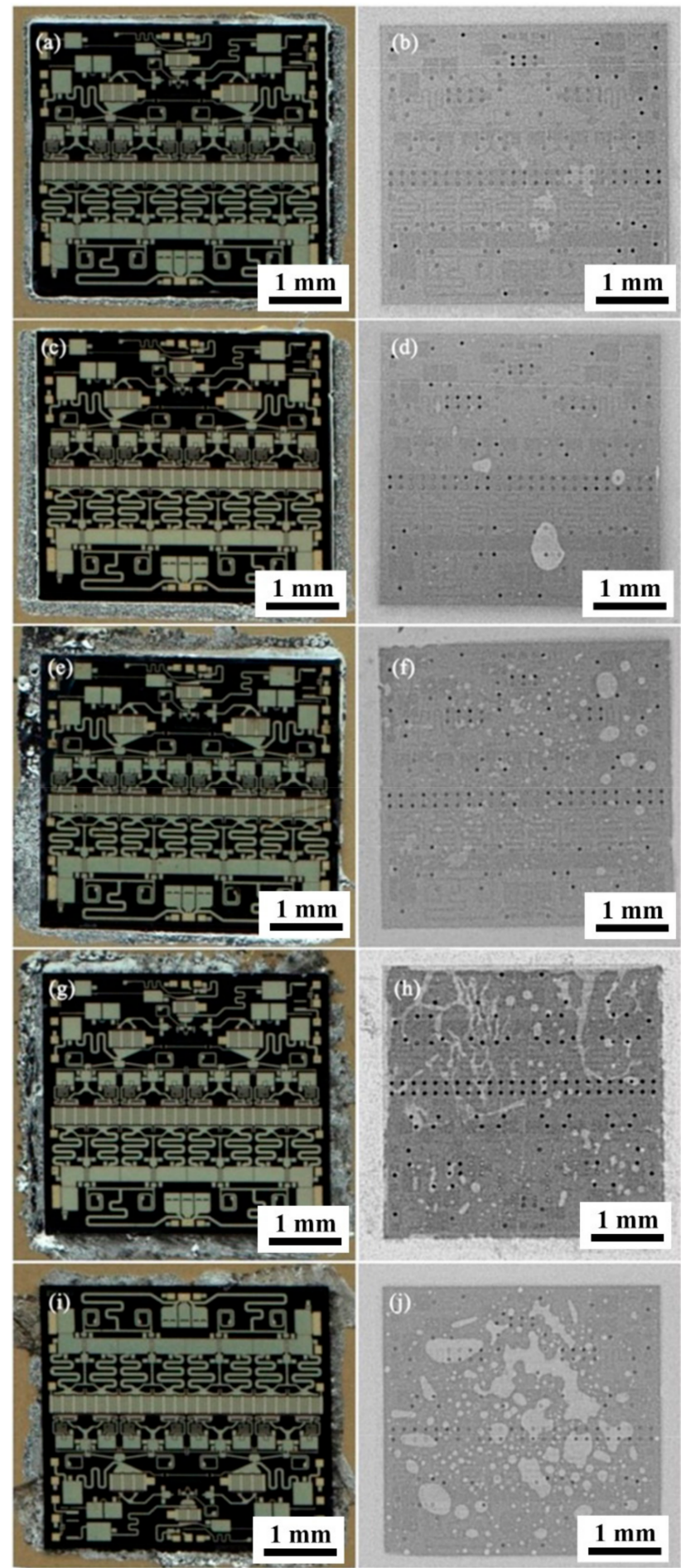

Figure 6. Appearances and X-ray inspection images of chips packaged using Au-20Sn solders with the oxygen content of: (a,b) 18 ppm; (c,d) 27 ppm;(e,f) 40 ppm; (g,h) 53 ppm; (i,j) 77 ppm. 


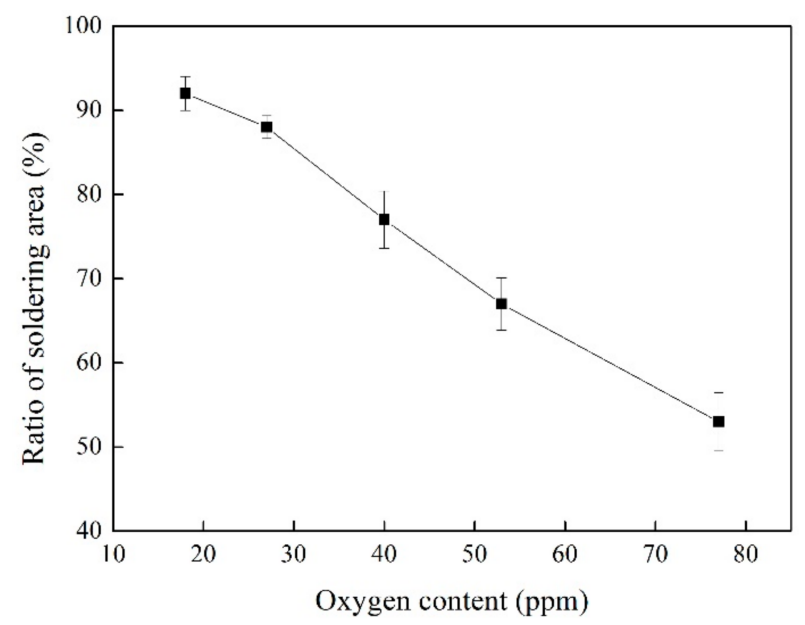

Figure 7. Relationship between oxygen content in the Au-20Sn solder and ratio of soldering area of in the chips packaged using these Au-Sn solders.

\section{Conclusions}

The effects of a trace content of oxygen on performances of the Au-20Sn solder and $\mathrm{Au}-\mathrm{Sn} / \mathrm{Cu}$ solder joint were comprehensively investigated. Based on the experimental results and discussions, the following conclusions can be drawn:

(1) The wettability and spreading performances of the Au-20Sn solder deteriorates sharply with the increasing oxygen content, because the Sn-O oxides film at the surface of the liquid solder increases the surface tension and decreases the fluidity. When the oxygen content increased from 18 to $77 \mathrm{ppm}$, the spreading area of the solder on $\mathrm{Cu}$ decreased sharply by $47 \%$.

(2) Pores and microcracks appeared in the solder joint interface packaged using solders with a relatively high content of oxygen, which were induced by the included oxides and gas elements. These interfacial defects made the shear strength of the Au-Sn/Cu solder joint decrease from 56.6 to $31.7 \mathrm{MPa}$ when the oxygen content increased from 18 to $77 \mathrm{ppm}$.

(3) The package gas tightness decreases with increasing oxygen content. Using a Au-20Sn solder containing higher than $40 \mathrm{ppm}$ of oxygen, the leakage rate of the packaged flat sapphire optical window was overly high and unqualified.

(4) The increasing trace oxygen content in the Au-20Sn solder made more voids appear in the solder layer of the fluxless soldered chip and resulted in an obvious decrease in the ratio of soldering area; meanwhile, the solder edge became uneven, and more obvious surface oxidation occurred.

Author Contributions: Conceptualization, S.X.; methodology, Y.L.; software, D.W.; validation, Y.L.; formal analysis, D.W.; investigation, Y.L.; resources, Y.Z.; data curation, Y.Z.; writing—original draft preparation, Y.L.; writing-review and editing, L.W.; visualization, D.W.; supervision, L.W.; project administration, Y.L.; funding acquisition, S.X. All authors have read and agreed to the published version of the manuscript.

Funding: This work was funded by the National Natural Science Foundation of China, Grant No.51675269.

Informed Consent Statement: Not applicable.

Data Availability Statement: The data could be obtained from the corresponding author.

Acknowledgments: We gratefully acknowledge financial support from the National Natural Science Foundation of China (Grant No.51675269).

Conflicts of Interest: The authors declare no conflict of interest. 


\section{References}

1. Yoon, J.W.; Chun, H.S.; Jung, S.B. Reliability evaluation of Au-20Sn flip chip solder bump fabricated by sequential electro-plating method with Sn and Au. Mater. Sci. Eng. A 2008, 473, 119-125. [CrossRef]

2. Chung, H.-M.; Chen, C.-M.; Lin, C.-P.; Chen, C.-J. Microstructural evolution of the Au-20wt.\% Sn solder on the Cu substrate during reflow. J. Alloy. Compd. 2009, 485, 219-224. [CrossRef]

3. Zhang, G.S.; Jing, H.Y.; Xu, L.Y.; Wei, J.; Han, Y.D. Creep behavior of eutectic 80Au/20Sn solder alloy. J. Alloys Compd. 2009, 476, 138-141. [CrossRef]

4. Elmer, J.W.; Mulay, R.P. Superplastic creep of AuSn eutectic solder alloy. Scripta Mater. 2016, 120, 14-18. [CrossRef]

5. Zhu, Z.X.; Li, C.C.; Liao, L.L.; Liu, C.K.; Kao, C.R. Au-Sn bonding material for the assembly of power integrated circuit module. J. Alloys Compd. 2016, 671, 340-345. [CrossRef]

6. Lai, Y.T.; Liu, C.Y. Study of wetting reaction between eutectic AuSn and Au foil. J. Electron. Mater. 2006, 35, 28-34. [CrossRef]

7. Yoon, J.W.; Chun, H.S.; Jung, S.B. Reliability analysis of Au-Sn flip-chip solder bump fabricated by co-electroplating. J. Mater. Res. 2007, 22, 1219-1229. [CrossRef]

8. Kim, J.; Schoeller, H.; Cho, J.; Park, S. Effect of Oxidation on Indium Solderability. J. Electron. Mater. 2007, 37, 483-489. [CrossRef]

9. Lee, J.; Tanaka, T.; Yamamoto, M.; Hara, S. Effect of Oxygen on Surface Tension of Liquid Ag-Sn Alloys. Mater. Trans. 2004, 45, 625-629. [CrossRef]

10. Yunus, M.; Srihari, K.; Pitarresi, J.; Primavera, A. Effect of voids on the reliability of BGA/CSP solder joints. Microelectron. Reliab. 2003, 43, 2077-2086. [CrossRef]

11. Jiang, J.; Lee, J.E.; Kim, K.S.; Suganuma, K. Oxidation behavior of Sn-Zn solders under high-temperature and high-humidity condi-tions. J. Alloys Compd. 2008, 462, 244-251. [CrossRef]

12. Kuhmann, J.F.; Preuss, A.; Adolphi, B.; Maly, K.; Wirth, T.; Oesterle, W.; Pittroff, W.; Weyer, G.; Fanciulli, M. Oxidation and reduction kinetics of eutectic $\mathrm{SnPb}$, InSn, and AuSn: A knowledge base for fluxless solder bonding applications. IEEE. T. Comp . Pack. Man: Part, C. 1998, 21, 134-141. [CrossRef]

13. Zhao, J.; Yuan, Q.; Kan, X.; Yang, J.; Yang, F. A low feed-through 3D vacuum packaging technique with silicon vias for RF MEMS reso-nators. J. Micromech. Microeng. 2016, 27, 014003. [CrossRef]

14. Yoon, J.W.; Chun, H.S.; Koo, J.M.; Jung, S.B. Au-Sn flip-chip solder bump for microelectronic and optoelectronic applications. Microsyst Technol. 2007, 13, 1463-1469. [CrossRef]

15. Wang, L.; Xue, S.; Liu, H. Effect of oxygen content on wettability, microstructure and solderability of Au-20Sn solders. J. Mater. Sci. Mater. Electron. 2018, 29, 21130-21137. [CrossRef]

16. Zhang, D. Wetting of Ceramics by Molten Mg and Effect of Evaporation; Jilin University: Changchun, China, 2012.

17. Wei, X. Preparation and Related Fundamental Research on AuSn20 Eutectic Solder for Electronic Packaging; Central South University: Changsha, China, 2014.

18. Wei, X.; Wang, R.; Peng, C.; Yan, F.E.N.G.; Zhu, X.W. Microstructural evolutions of Cu(Ni)/AuSn/Ni joints during reflow. Prog. Nat. Sci-Mater. 2011, 21, 347-354. [CrossRef]

19. Xu, J.; Wu, M.; Pu, J.; Xue, S. Novel Au-Based Solder Alloys: A Potential Answer for Electrical Packaging Problem. Adv. Mater. Sci. Eng. 2020, 2020, 4969647. [CrossRef]

20. Khanna, P.K.; Bhatnagar, S.K.; Gust, W. Analysis of packaging and sealing techniques for microelectronic modules and recent advances. Microelectron. Int. 1999, 16, 8-12. [CrossRef]

21. Gao, L.; Bao, X.; Gu, W.; Li, R. Development and applications of hermetic sealing technology for microelectronics modulus. Electr. Weld. Mach. 2016, 46, 105-108. [CrossRef]

22. Wang, Y. The Parameters of Brazing Process Have an Influence on Brazing Rate; Chongqing University of Technology: Chongqing, China, 2013. 